\title{
Bubble Electret-Elastomer Piezoelectric Transducer
}

\author{
Ryszard Kacprzyk $\mathbb{D}$ and Agnieszka Mirkowska * $\mathbb{D}$ \\ Department of Electrical Engineering Fundamentals, Wroclaw University of Science and Technology, \\ 50-377 Wroclaw, Poland; ryszard.kacprzyk@pwr.edu.pl \\ * Correspondence: agnieszka.mirkowska@pwr.edu.pl; Tel.: +48-71-320-24-37
}

Received: 22 April 2020; Accepted: 3 June 2020; Published: 5 June 2020

\begin{abstract}
Ferroelectret-based piezoelectric transducers are, nowadays, commonly used in energy harvesting applications due to their high piezoelectric activity. Unfortunately, the processing properties of such materials are limited, and new solutions are sought. This paper presents a new solution of a piezoelectric transducer containing electret bubbles immersed in an elastomer matrix. Application of a gas-filled dielectric bubble as the fundamental cell of the piezo-active structure is discussed. A simplified model of the structure, containing electret thin-wall bubbles and elastomer dielectric filling, was applied to determine the value of the piezoelectric coefficient, $d_{33}$. An exemplary structure containing piezo-active bubbles, made of an electret material, immersed in an elastomer filling is presented. The influence of the mechanical and electrical properties of particular components on the structure piezoelectric properties are experimentally examined and confirmed. The quasi-static method was used to measure the piezoelectric coefficient, $d_{33}$. The separation of requirements related to the mechanical and electrical properties of the transducer is discussed.
\end{abstract}

Keywords: dielectric composites; dielectrics; energy harvester; ferroelectrets; piezoelectrets; piezoelectric materials

\section{Introduction}

Energy harvesting from different renewable resources is presently broadly studied. One of the prospective solutions is energy harvesting from vibrations, based on the application of piezoelectric transducers [1,2]. Conventionally used piezoelectric transducers are based mainly on materials with spontaneous electric polarization, such as ceramics or polyvinylidene fluoride (PVDF) foils. The piezoelectric properties of structures are typically characterized by piezoelectric coefficient $d_{i j}$, which can be measured using different methods, such as quasi-static, dynamic, and other [3]. In the most popular lead zirconate titanate (PZT) ceramics and composites, the $d_{33}$ component reaches $600 \mathrm{pC} / \mathrm{N}$ [4], while, in PVDF foils, $d_{33} \leq 30 \mathrm{pC} / \mathrm{N}$ is observed [5]. For well-known zinc oxide ( $\left.\mathrm{ZnO}\right)$, the coefficient $d_{33}$ reaches $12 \mathrm{pC} / \mathrm{N}[6,7]$, while, for lead-free $(\mathrm{K}, \mathrm{Na}) \mathrm{NbO}_{3}$ ceramics, it almost reaches $500 \mathrm{pC} / \mathrm{N}$; however, to reach the highest values complex processing is required [8].

The piezoelectric phenomenon occurs due to different physical mechanisms. One of them is the generation of inhomogeneous strain in a dielectric containing a space charge density [9]. In practice, the requirement of inhomogeneous strain is realized by the application of layered dielectric structures containing layers exhibiting different mechanical properties (elasticity coefficient). Dielectrics possessing good electret properties (sufficiently long charge life-time), like poly(tetrafluoroethylene) (PTFE) or polypropylene (PP), simultaneously exhibit a relatively high Young's modulus, which is usually of the order of $10^{9} \mathrm{~Pa}$ [10]. This parameter seriously limits the direct application of such dielectrics in the construction of piezoelectric transducers. Models describing the piezoelectric properties of layered structures have shown that the presence of at least one dielectric layer with a relatively high elasticity (low value of Young's modulus $Y$, which should be on the level of $10^{5} \mathrm{~Pa}$ or lower) is one of 
the fundamental requirements [11-13]. This mechanical demand may be obtained by specific polymer processing, such as 3D printing [14], foaming, stretching, thermoforming, and others [15]. Structures made of different electret materials, such as polypropylene (PP) [16], cross-linked PP-XPP [17], poly(tetrafluoroethylene) (PTFE) [18], fluoroethylenepropylene (FEP) [19], poly(ethylene tetraphtalate) (PET) [20], poly(ethylene naphthalate) (PEN) [21], or cyclo-olefins polymers [22], have been investigated for many years. The mentioned polymers were used in a 'dispersed' form as gas-electret composites, so-called ferroelectrets. The name 'ferroelectrets' is associated with the fact that these gas-electret composites exhibit $P-E$ (polarization-electric field intensity) hysteresis when submitted to high electric fields [23]. Ferroelectrets usually contain thin-wall, usually open, tubular gas channels or lens-like gas voids. Such a construction allows to obtain the effective Young's modulus on the level of $10^{5} 10^{6-} \mathrm{Pa}$, with preservation of charge-stability [24], and finally, receive the piezoelectric coefficient $d_{33}$ exceeding $1000 \mathrm{pC} / \mathrm{N}$ [25]. Relatively high elasticity of ferroelectrets and their high $d_{33}$ coefficient cause that ferroelectret materials are frequently applied in energy harvesters solutions [26-28].

Application of particular thin-wall electret elements in ferroelectrets is necessary due to two fundamental requirements: (1) the charge-storage abilities (the thinner the wall, the higher the surface charge density possible to deposit on the gas void surfaces), and (2) lowering of the effective Young's modulus of the dielectric composite [11,29]. Ferroelectrets with a coefficient of $d_{33}>100 \mathrm{pC} / \mathrm{N}$ contain a great deal of gas inside thin-wall tube-like electret channels, which makes them very pliable to heavy strain. The piezoelectric properties of ferroelectrets can be determined using two-, three- or multi-layer models [11,12]. All of these leads to the conclusion that structures with a relatively high value of $d_{33}$ can be obtained by: (1) increasing the surface charge density on the inner surface of gas voids, and (2) lowering of the effective Young's modulus of the whole structure. Moreover, the technical application of ferroelectrets requires material property stability, such as charge or thermal stability in time. The charge stability depends highly on the temperature-the higher the temperature, the faster the charge decay. For PTFE, thermal stability reaches $130{ }^{\circ} \mathrm{C}$ [30]; the charge stability may last years, and chemical processing leading to improved charge stability is possible [31]. In addition, ferroelectret-based transducers are characterized by a low coupling factor, but the extremely low acoustic impedance of such materials compensate for this [32]. It should be noted that the number of electret materials (exhibiting a high value of Young's modulus, $Y$ ) and their processing properties are limited, so new solutions are being explored.

In this paper, a new solution of an electret-elastomer composite is discussed. In the case of thin-wall electret bubbles immersed in a non-conducting elastomer, the composite allows to separate the roles of the components, particularly, requirements related to their mechanical (Young's modulus) and electrical (charge stability) properties. Stability of piezoelectric coefficient $d_{33}$ is determined by the charge storage properties of the electret bubbles, and the mechanical strain (due to the external stress) is mainly determined by the properties of the used elastomer characterized by the value of Young's modulus $-Y_{\mathrm{e}}$. The application of dielectric composites, containing electret bubbles immersed in an elastomer matrix widen the range of dielectric materials that can be applied in piezoelectric transducer constructions.

\section{Structural Model}

The cross-section of the bubble electret-elastomer transducer is shown in Figure 1. The piezoelectric transducer contains two essential layers: external elastomer filling as the forming layer (1), and an active electret layer consisting of gas bubbles with bipolar charge $\pm q_{\mathrm{s}}$ distributed on their inner surfaces of the thin electret "shell" (2). Also the two rigid metal electrodes were applied on the outside sides of the sample (3). 


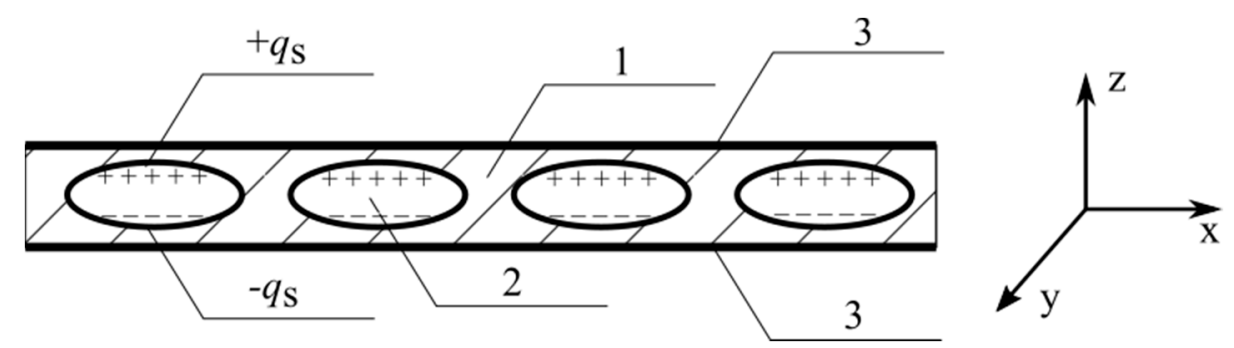

Figure 1. Bubble electret-elastomer transducer with bi-polar charge $q_{\mathrm{s}}$ deposited on the inner surfaces of the electret bubble, where 1-forming layer made of dielectric elastomer, 2-electret bubble, and 3-electrodes.

A simplified model of a single electret bubble immersed in an elastomer is presented in Figure 2. The model, with cylindrical symmetry (structure axis perpendicular to the layers surface), consists of three main layers: two A layers made of elastomer, characterized by elasticity coefficient $Y_{\mathrm{e}}$ and a thickness of $x_{1}$, and a non-uniform B-layer with a total thickness of $x_{2}$, made of an electret bubble and elastomer surrounding characterized by the equivalent Young's modulus, $Y_{2}$. The electret bubble has uniform walls with a thickness of $h$ and is made of dielectric characterized by its Young's modulus $-Y_{1}$-and electric permittivity $-\varepsilon_{1}$. The properties of the gas layer are given by gas-void bubble thickness $x_{\mathrm{p}}$ and gas electric permittivity $\varepsilon_{\mathrm{p}}$.

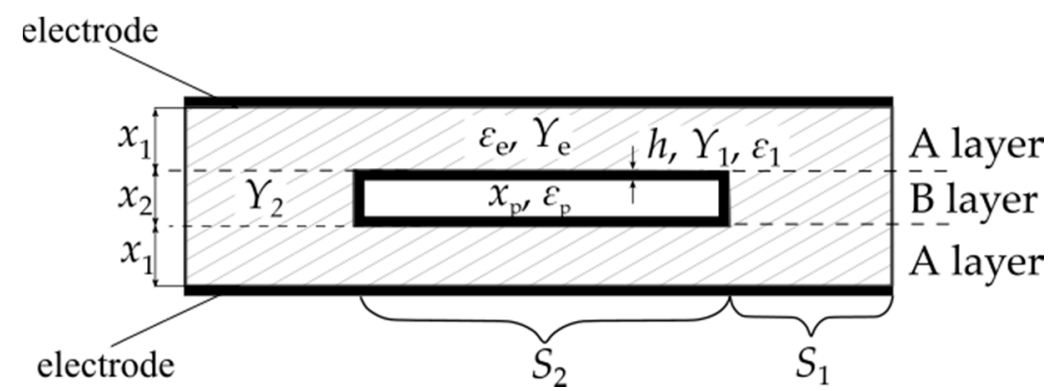

Figure 2. The simplified model of a dielectric bubble immersed in an elastomer containing two elastomer layers-A (with thickness $x_{1}$, electric permittivity of an elastomer $\varepsilon_{\mathrm{e}}$ and Young's modulus of an elastomer $Y_{\mathrm{e}}$ ) and electret bubble-elastomer layer B with the total thickness of $x_{2}$ and effective Young's modulus of the whole layer $Y_{2}$. The area $S_{2}$ is the area of electret bubble (the properties of electret wall are given by $h$-wall thickness, $Y_{1}$-Young's modulus and $\varepsilon_{1}$-electric permittivity of electret material) and $S_{2}$-the area of an elastomer in layer B. The properties of gas inside the bubble are given by gas electric permittivity $\varepsilon_{\mathrm{p}}$ and gas void height $x_{\mathrm{p}}$.

The area of the elastomer part of layer $\mathrm{B}$ is given by $S_{1}$, which is smaller than the area of electret bubble $S_{2}$. The charge is stored only on area $S_{2}$ on the inner surface of the bubble. Thus, effective charge $q_{\mathrm{s}}$ is reduced by an $S_{2} / S$ ratio due to $q_{\mathrm{s}}{ }^{\prime}$ possible to store in the total area $S$. Assuming that a bubble is a cylindrical pastille, and ignoring the edge effects, the piezoelectric properties of the B-layer can be determined using a 3-layer dielectric model [29]. Thus, the $d_{33 \mathrm{~B}}$ coefficient is for the B-layer (Figure 2) only, and for assumption $t_{m}>>\tau_{\mathrm{Me}}$ (measurements carried out for the time $t_{\mathrm{m}}$ much shorter than $\tau_{\mathrm{Me}}$-the Maxwell time constant for the elastomer) it is given by the following relation:

$$
d_{33 \mathrm{~B}}=\frac{2 q_{\mathrm{s}}^{\prime} \varepsilon_{1} \varepsilon_{\mathrm{p}} h x_{\mathrm{p}}}{\left(h \varepsilon_{\mathrm{p}}+x_{\mathrm{p}} \varepsilon_{1}\right)^{2}} \cdot\left(\frac{1}{Y_{2}}-\frac{1}{Y_{1}}\right)
$$

where $q_{\mathrm{s}}{ }^{\prime}=q_{\mathrm{s}} \cdot S_{2} / S$ and $q_{\mathrm{s}}$ is the charge possible to store on the total area $S$ of the sample. 
Assuming the adiabatic compression of the bubble with the initial pressure much lower than $Y_{2}$ and for assumption $Y_{2}<<Y_{1}$, the $d_{33 \mathrm{~B}}$ coefficient is:

$$
d_{33 \mathrm{~B}} \cong \frac{2 q_{\mathrm{s}}^{\prime} \varepsilon_{1} \varepsilon_{\mathrm{p}} h x_{\mathrm{p}}}{\left(h \varepsilon_{\mathrm{p}}+x_{\mathrm{p}} \varepsilon_{1}\right)^{2}} \cdot\left(\frac{1}{Y_{2}}\right) .
$$

Considering, thickness $h$ of a thin electret wall of the bubble (electret 'shell') filled with gas (air) and satisfies the relation $h<<x_{2}$ and $x_{\mathrm{p}} \approx x_{2}$, Equation (2) can be rewritten as:

$$
d_{33 \mathrm{~B}} \cong \frac{2 q_{\mathrm{s}}^{\prime} \varepsilon_{\mathrm{p}} h}{\varepsilon_{1} x_{2}} \cdot \frac{1}{Y_{2}}
$$

The equivalent Young's modulus, $Y_{2}$ (for the B-layer), is determined by the elasticity of the elastomer ring (around the bubble) and was determined using the model shown in Figure 3. Assuming that the B-layer strain is the same as the strain of the elastomer ring (Figure 3b), and if Hook's law is in power, the equivalent Young's modulus $Y_{2}$ is given as:

$$
Y_{2}=Y_{\mathrm{e}} \frac{S_{1}}{S}
$$

where $Y_{\mathrm{e}}$ is the Young's modulus of an elastomer, $S_{1}$-surface area of the elastomer ring, and $S=S_{1}+S_{2}$-total surface of the layer.

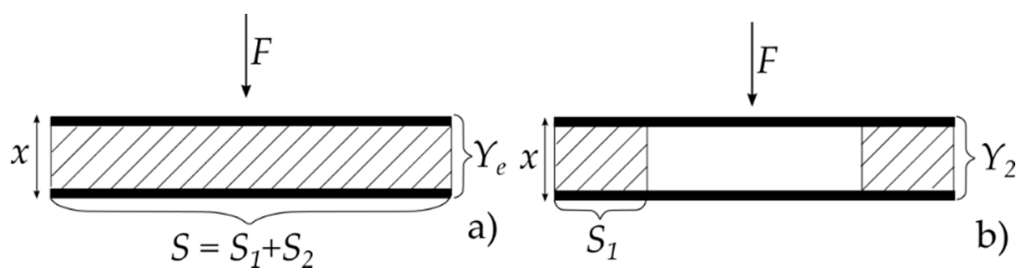

Figure 3. Deformation of (a) plain elastomer layer and (b) elastomer-ring, under external stress $F$, where $x$ is the thickness of both layers, $Y_{\mathrm{e}}$-Young's modulus of the plain elastomer layer with the area $S, Y_{2}$-effective Young's modulus of the elastomer ring with the area $S_{1}$.

Considering the charge stored on the inner surface of the bubbles only (on the area $\left(S_{2}\right)$ ) and substituting Equation (4) into Equation (3) one can finally obtain:

$$
d_{33 \mathrm{~B}} \cong \frac{2 q_{\mathrm{s}} \varepsilon_{\mathrm{p}} h}{\varepsilon_{1} x_{2}} \cdot \frac{S_{2}}{S_{1}} \cdot\left(\frac{1}{Y_{\mathrm{e}}}\right) .
$$

The $d_{33}$ coefficient measured on the electrodes for the structure as shown in Figure 2 is reduced by the capacitances of A-layers (elastomer layers with thickness $x_{1}$ ). The phenomenon can be described by the capacitive model shown in Figure 4. Assuming $S_{1}<<S_{2}$, the capacitance $C_{\mathrm{e}}<<C_{\mathrm{b}}$, where $C_{\mathrm{e}}$ is the capacitance of the elastomer part, and $C_{b}$ is the capacitance of the bubble (see Figure 2). Hence, ignoring the edge effects, the total capacitance of the B-layer $\left(C_{B}\right)$ is approximately equal to the capacitance of bubble $C_{\mathrm{b}}$. The model allows to determine the $d_{33}$ coefficient from the simplified relation:

$$
d_{33} \cong d_{33 \mathrm{~B}} \frac{C_{\mathrm{A}}}{C_{\mathrm{A}}+C_{\mathrm{B}}},
$$

where $C_{\mathrm{A}}$ is the capacitance of both A-layers (in series) and $C_{\mathrm{B}}$ is the capacitance of layer $\mathrm{B}$. 


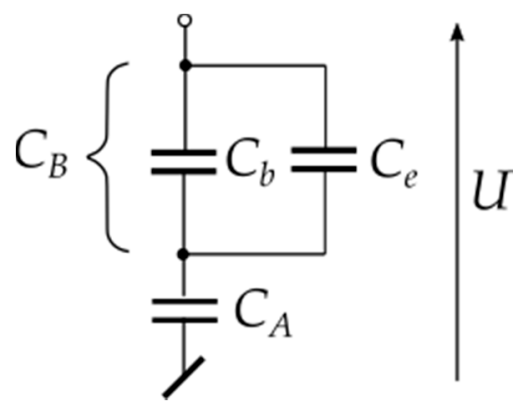

Figure 4. Capacitance model of a layered dielectric structure, where $C_{\mathrm{A}}$ is a parallel capacitance of both A-layers, $C_{\mathrm{e}}$ is the capacitance of the elastomer ring, $C_{\mathrm{b}}$ is the capacitance of the bubble and $C_{\mathrm{B}}$ is the capacitance of the whole B-layer.

Assuming that $S_{1}<<S$, (or $\left.C_{\mathrm{B}} \approx C_{\mathrm{b}}\right)$, the final value for the $d_{33}$ coefficient can be determined from the following relation:

$$
d_{33} \cong d_{33 \mathrm{~B}} \cdot \frac{1}{1+2 \frac{x_{1}}{x_{2}} \cdot \frac{\varepsilon_{\mathrm{p}}}{\varepsilon_{\mathrm{e}}}},
$$

where $\varepsilon_{\mathrm{p}}$ and $\varepsilon_{\mathrm{e}}$ are the electric permittivity of the gas and elastomer, respectively. According to Equation (7), when the thicknesses of layers A and B satisfy the relation $x_{1}<<x_{2}$, the $d_{33}$ coefficient is not practically reduced by capacitance $C_{\mathrm{A}}$ of elastomer layer $\mathrm{A}$.

\section{Materials and Methods}

\subsection{Sample Preparation}

The electret bubbles were thermoformed from a polytetrafluoroethylene (PTFE) electret tube. The PTFE polymer was chosen due to its good charge and thermal stability [33]. The tube with inner and outer diameters of $500 \pm 60 \mathrm{~m}$ and $1200 \pm 200 \mathrm{~m}$, respectively, was flattened and then welded at equal intervals, $4.5 \pm 0.3 \mathrm{~mm}$. The electret wall thickness after flattening was $200 \pm 20 \mu \mathrm{m}$, and the height of the air gap was equal to $100 \pm 20 \mu \mathrm{m}$ (see Figure $5 \mathrm{c}, \mathrm{d}$ ).

The pillow-shaped electret bubbles were immersed into an elastomer-Gumosil ${ }^{\circledR}$ AD-1. The prepared samples were dried for 24 hours in the air, at a temperature of $25{ }^{\circ} \mathrm{C}$ and humidity of $\mathrm{RH}=45 \%$. The samples with irregular (see Figure $5 \mathrm{a}$ ) and regular (Figure $5 \mathrm{~b}$ ) bubble distributions were prepared. Finally, the samples were covered by self-adhesive copper electrodes. The final dimensions of the bubbles-elastomer composite sample were equal to $20 \times 20 \times 2 \mathrm{~mm}$ and the 9 bubbles, with a total surface $S_{2}=90 \mathrm{~mm}^{2}$, were immersed in parallel.
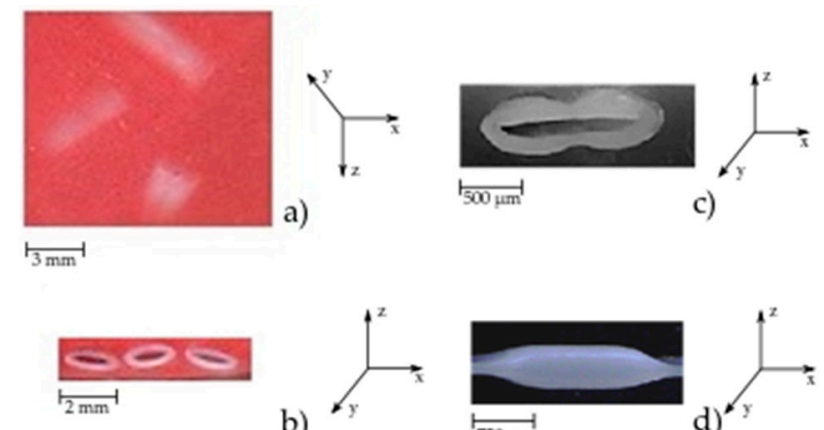

b)<smiles>CC(C)C(C)C(=O)O</smiles>

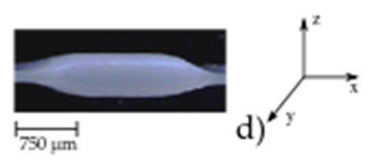

Figure 5. Electret-elastomer transducer: (a) electret pillow-shaped bubbles immersed in an elastomer (irregular bubbles distribution), (b) cross-section of the whole sample (regular bubbles distribution), (c) cross-section perpendicularly to the bubble's axis, and (d) back view of a pillow-shaped bubble. 


\subsection{Sample Charging}

Bi-polar charge distribution along the inner surfaces of bubbles were obtained using the corona-charging process (Figure 6). The high voltage needle electrode (1) was mounted in a distance of $15 \mathrm{~mm}$ above the non-metalized side of a sample (2). The sample was placed on a grounded metal table (3). Corona discharge was carried out under conditions: DC polarization voltage $U_{\text {pol }}=+10 \mathrm{kV}$, polarization time $t_{\mathrm{pol}}=30 \mathrm{~s}$. A TREK model $610 \mathrm{E}$ was used as the high voltage DC power supply (4).

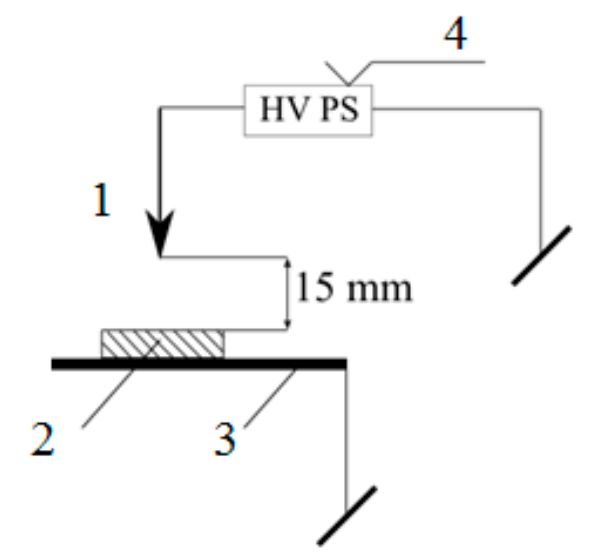

Figure 6. An arrangement for corona-charging of samples, where 1-needle electrode, 2-sample, 3-grounded table, and 4-high voltage power supply.

\subsection{Static Piezoelectric Coefficient Measurement}

Measurements of the piezoelectric coefficient $d_{33}$ were performed by applying the quasi-static method [3,34]. The prepared arrangement is illustrated in Figure 7. The prepared sample (1) was placed between the isolated rigid measuring electrode (2) and grounded, movable electrode (3) fixed to the pan (4). The cylindrical electrode with a diameter equal to $20 \mathrm{~mm}$ and was applied. Voltage measurements were carried out using the electrometer (5) RFT-6302 with an attached measurement capacitor $1.5 \mathrm{nF}$ (6). The total capacity of the voltage measurement system (including measurement capacitor, the cable and voltmeter input capacitances and sample capacitance) was equal to $C_{\mathrm{T}}=1.65 \mathrm{nF}$. For shielding from external electric fields, the whole system was placed in a grounded Faraday's cage (7) The controlled stress was applied to the samples using the weights (8) placed on the pan (4). Mass of the weights was determined using a quartz scale. The total mass of the movable part containing the electrode (4) was $134 \mathrm{~g}$.

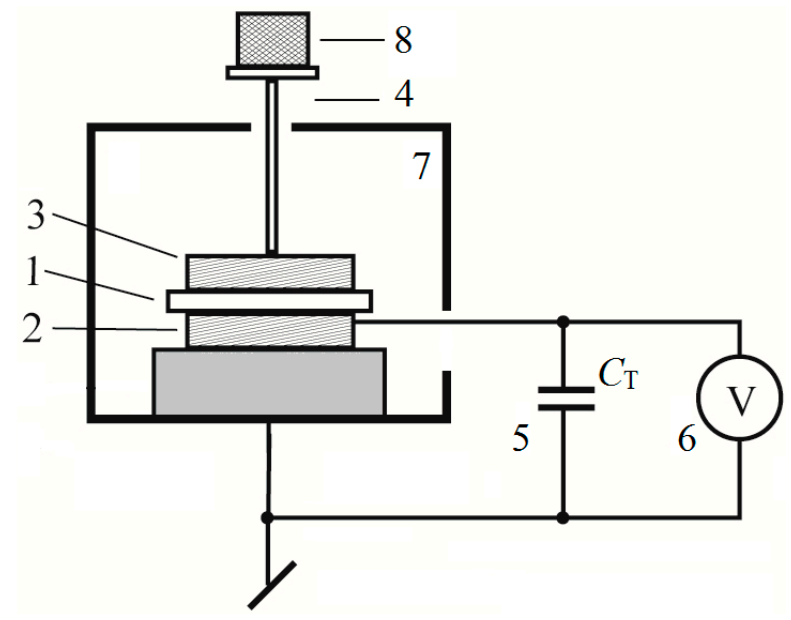

Figure 7. An arrangement for measuring the piezoelectric coefficient $d_{33}$ using a static method, where 1-sample, 2-isolated measuring electrode, 3-grounded electrode, 4 -pan, 5-total capacitance $C_{\mathrm{T}}$, 6-electrometer, 7-Faraday's cage, and 8-load. 
The $d_{33}$ coefficient was calculated using the relation:

$$
d_{33}=\frac{\Delta U \cdot C_{\mathrm{T}}}{\Delta m \cdot g}
$$

where $C_{\mathrm{T}}=1.65 \mathrm{nF}$ is the total capacitance of the voltage measuring system, $\Delta U$ is the voltage change measured after application of the known stress (static force) within time $t_{\mathrm{m}}<<\tau_{\mathrm{Me}}, \Delta m$ is the mass of the load, and $g$ is the gravitational acceleration $\left(9.81 \mathrm{~m} / \mathrm{s}^{2}\right)$.

Assuming that the $d_{33}$ measurement, using the described method, is carried out within time $t_{\mathrm{m}}$ (equal to a few seconds) and relation $t_{\mathrm{m}}<<\tau_{\mathrm{Me}}$, is satisfied, the transient effects (in elastomer) should not affect the measured $d_{33}$ value.

\section{Results}

\subsection{Properties of Applied Materials}

The properties of the elastomer were examined using a $500 \mu \mathrm{m}$ thick homogeneous sample. After polymerization, the charge decay characteristic, electric permittivity $\varepsilon_{\mathrm{e}}$ and Young's modulus were determined. Approached value of Maxwell-time constant $\tau_{\mathrm{Me}}$ was determined from the equivalent voltage $U_{\mathrm{z}}(t)$ decay characteristic (see Figure 6). The time $t_{\mathrm{e}}$ determined for $\left|U_{\mathrm{z}} / U_{\mathrm{z} 0}\right|=1 / \mathrm{e}$ was assumed in the first approximation to be equal to $\tau_{\mathrm{Me}}$, where $U_{z 0}$ is the initial value of the equivalent voltage just after corona charging [35]. According to Figure 8 , the time $t_{\mathrm{e}} \approx \tau_{\mathrm{Me}}$ is equal to $\tau_{\mathrm{Me}} \approx 100 \pm 10 \mathrm{~s}$.

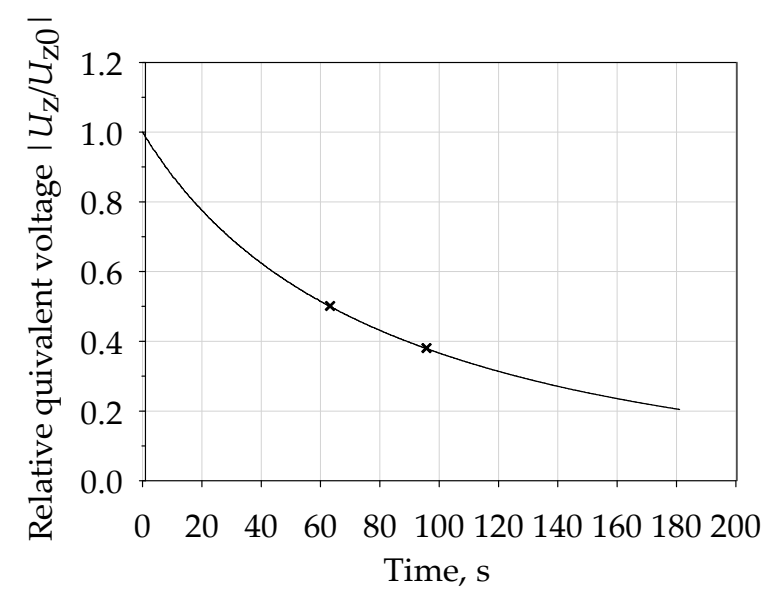

Figure 8. An experimental charge decay for a $500-\mu m$-thick Gumosil ${ }^{\circledR}$ layer.

The measured relative electric permittivity $\varepsilon_{\mathrm{e}}$ of elastomer was on the level $3.29-3.37(20-50,000 \mathrm{~Hz})$, so the value $\varepsilon_{\mathrm{e}}=3.3$ (measured for $1 \mathrm{kHz}$ ) was assumed for the calculations.

The Young's modulus of elastomer $Y_{\mathrm{e}}$ was measured using the setup presented in [29]. As the Young's modulus of elastomers is pressure-dependent and usually non-linear [36], pressure $p$ applied in Young's modulus measurements were the same as in piezoelectric coefficient measurements. Finally, the value of $Y_{\mathrm{e}}=86-98 \mathrm{kPa}$ was measured (for pressure $p$ in a range between 3.1 and $8.7 \mathrm{kPa}$ ). Finally, $Y_{\mathrm{e}}=90 \mathrm{kPa}$ was assumed for the calculations.

\subsection{Measurements and Calculations of $d_{33}$ Coefficient}

Calculations of the $d_{33 \text { B }}$ and $d_{33}$ values were carried out using Equations (5) and (7), considering the following data: Young's modulus of an elastomer $Y_{\mathrm{e}}=9.0 \cdot 10^{4} \mathrm{~Pa}$, electric relative permittivity of an elastomer $\varepsilon_{\mathrm{e}}=3.3$ (measured at $1 \mathrm{kHz}$ ); the ratio $\left(S_{2} / S_{1}\right)=0.3$, thickness: $h=200 \pm 20 \mu \mathrm{m}$, $x_{1}=750 \pm 20 \mu \mathrm{m}, x_{2}=500 \pm 20 \mu \mathrm{m}$ (determined from observation of the bubble cross-sections under optical microscope). 
The approached value of maximum surface charge density $q_{\mathrm{sMAX}}$ possible to store in the inner parts of the bubble was determined using the relation [37]:

$$
q_{\mathrm{SMAX}}=\varepsilon_{0}\left(\varepsilon_{\mathrm{p}}+\varepsilon_{1} \frac{x_{\mathrm{p}}}{2 h}\right) E_{\mathrm{k}}
$$

where critical electric field $E_{\mathrm{k}}=8.6 \mathrm{MV} / \mathrm{m}$ was calculated using Paschen's law for the air gap thickness $x_{\mathrm{p}}=100 \mu \mathrm{m}$. The calculated value of the $q_{\mathrm{sMAX}}$ is on the level of $114 \mu \mathrm{C} / \mathrm{m}^{2}$. Results of experiments have shown $[29,37]$, that the real surface charge density $q_{\mathrm{s}}$ of the charge stored along the surface of the gas void is smaller than the value estimated using Equation (9). So finally for the $d_{33}$ calculations the value $q_{\mathrm{s}}=50 \mu \mathrm{C} / \mathrm{m}^{2}$ was assumed (according to [29]). Using the above data, the values of $d_{33 \mathrm{~B}}=69 \mathrm{pC} / \mathrm{N}$ and $d_{33}=36 \mathrm{pC} / \mathrm{N}$ were finally determined using Equations (5) and (7).

For validation of the presented model, the measurements of the $d_{33}$ coefficient were carried out on the described structures. Results obtained for freshly charged structure and structures stored in the air in temperature of $25^{\circ} \mathrm{C}$ and humidity $\mathrm{RH}=45 \%$ are presented in Figure 9.

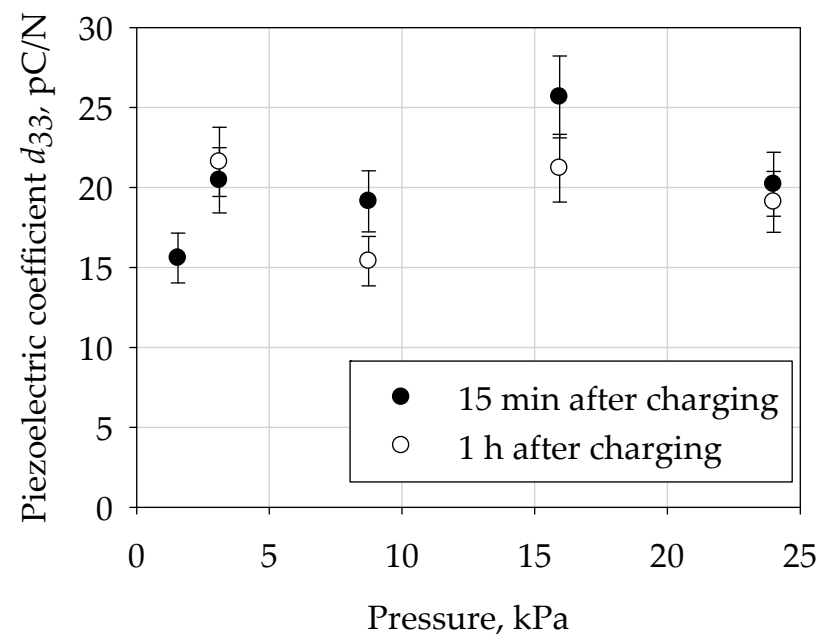

Figure 9. The pressure dependence of static piezoelectric coefficient $d_{33}$ for an exemplary sample.

The first measurement of $d_{33}$ coefficient was carried out $900 \mathrm{~s}$ after the structure polarization, so the charges stored in an elastomer should not have been present $\left(\tau_{\mathrm{Me}} \approx 100 \pm 10 \mathrm{~s}\right)$, and only the charges deposited on the inner surfaces of bubbles were supposed to be responsible for the observed quasi-piezoelectric phenomenon The measured static $d_{33}$ coefficient is in the range of $15-25 \mathrm{pC} / \mathrm{N}$, and it is almost constant in a pressure range between 2-24 $\mathrm{kPa}$ in contrast to ferroelectrets with open voids, where $d_{33}$ is decreasing with applied pressure [37]. According to the fact that charge decay of PTFE shows that the highest decrease of charge is observed in the first moments after charging [29,31], the same results may be apparent in the $d_{33}$ relation due to time after charging. As is presented in Figure 9 , the $d_{33}$ coefficient decreases in time-lower values of $d_{33}$ were obtained $1 \mathrm{~h}$ after charging in comparison to values obtained 15 minutes after charging in the pressure range $8-24 \mathrm{kPa}$.

The first measurement of $d_{33}$ coefficient was carried out $900 \mathrm{~s}$ after the structure polarization, so the charges stored in an elastomer should not have been present $\left(\tau_{\mathrm{Me}} \approx 100 \pm 10 \mathrm{~s}\right.$ ), and only the charges deposited on the inner surfaces of bubbles were supposed to be responsible for the observed quasi-piezoelectric phenomenon.

The dynamic piezoelectric coefficient measurements were also performed 3 hours after charging, using PM200 PiezoMeter System with a flat electrode with a diameter of $10 \mathrm{~mm}$. The applied static force was $F_{\text {stat }}=10.5 \pm 0.1 \mathrm{~N}$ (corresponding to pressure $p=134 \pm 2 \mathrm{kPa}$ ), dynamic force $F_{\text {dyn }}=0.25 \mathrm{~N}$, measuring frequency $f_{\mathrm{m}}=110 \mathrm{~Hz}$ (parameters recommended by the producer). The measured dynamic coefficient $d_{33 \mathrm{~d}}=16.8 \pm 2.0 \mathrm{pC} / \mathrm{N}$. 


\section{Discussion}

The simplified model describing the piezoelectric properties of the charged electret bubble-elastomer composite was presented in the paper. The presence of piezoelectric phenomena was confirmed experimentally for the exemplary structure. The obtained results illustrate the technological possibilities in obtaining the structures, where the mechanical properties and the geometrical stability of the whole structure are determined mainly by the elasticity of an elastomer-not by the elasticity of the electret material. The presence of upper and lower elastomer layers, with $x_{1}$ thickness, always reduce the $d_{33}$ coefficient, and that case was considered for a technological requirement only (see Figure $5 b)$. Thus, Equations (6) and (7) describe the worst situation $\left(x_{1}>0\right)$ from the point of view of the $d_{33}$ coefficient value. Moreover, Equations (4), (5) and (7) describe possibilities of obtaining composites with required $d_{33}$ coefficient and the mechanical stiffness of the whole structure. Hence, it widens the range of technological applications for piezo-active composites.

$d_{33}$ values obtained from calculations $(36 \mathrm{pC} / \mathrm{N})$ were higher in comparison to those measured (15-25 pC/N). The difference may result from the assumption $h<<x_{2}$, which was not fulfilled in the experiment. Higher thickness of the bubble wall $h$ leads directly to an increase of the value of effective Young's modulus for the layer B and finally to a decrease $d_{33}$ value.

The differences in measured and calculated values of $d_{33}$ may also result from the higher value of surface charge density $q_{\mathrm{s}}$ assumed for calculation in comparison to the average charge density obtained (on the inner parts of the bubbles) experimentally.

According to the presented model, the constructions of the piezo-active bubble electret-elastomer composites with higher piezoelectric coefficient $d_{33}$ are possible to obtain. Using bubbles with smaller wall thickness $h$, reduction of A-layers during the processing of a composite or application of elastomer with lower Young's modulus may lead to achieving transducers with higher piezoelectric coefficients, where the mechanical properties will be characterized by elastomer material. According to low Young's modulus of elastomers, the acoustic impedance of presented composites might also be an interesting issue for further research.

The further investigation and analysis of the charge storage properties of electret bubbles (charge density, surface distribution and influence of charging conditions) are recommended.

Author Contributions: Conceptualization, R.K.; methodology, R.K. and A.M.; validation, A.M.; formal analysis, R.K. and A.M.; investigation, A.M. and R.K.; resources, A.M. and R.K..; data curation, R.K. and A.M.; writing-original draft preparation, A.M..; writing—review and editing, R.K. and A.M.; visualization, R.K. and A.M.; supervision, R.K. and A.M.; project administration, R.K. and A.M.; funding acquisition, A.M. and R.K. All authors have read and agreed to the published version of the manuscript.

Funding: This research received no external funding. This work was financed by a statutory activity subsidy from the Polish Ministry of Science and Higher Education (PMSHE) for the Department of Electrical Engineering Fundamentals of Wroclaw University of Science and Technology.

Conflicts of Interest: The authors declare no competing financial interest.

Patents: Kacprzyk R., Grygorcewicz A., Materiał kompozytowy o właściwościach piezoelektrycznych, Eng. Composite material with piezoelectric properties, P422861, 14 April 2020.

\section{References}

1. Priya, S.; Song, H.; Zhou, Y.; Varghese, R.; Chopra, A.; Kim, S.; Kanno, I.; Wu, L.; Ha, D.S.; Ryu, J.; et al. A Review on Piezoelectric Energy Harvesting: Materials, Methods, and Circuits. Energy Harvest. Syst. 2017, 4, 3-39. [CrossRef]

2. Elahi, H.; Eugeni, M.; Gaudenzi, P. A Review on Mechanisms for Piezoelectric-Based Energy Harvesters. Energies 2018, 11, 1850. [CrossRef]

3. Hillenbrand, J.; Sessler, G.M. Quasistatic and Dynamic Piezoelectric Coefficients of Polymer Foams and Polymer Film Systems. IEEE Trans. Dielectr. Electr. Insul. 2004, 11, 72-79. [CrossRef]

4. Gamboa, B.; Bhalla, A.; Guo, R. Assessment of PZT (Soft/Hard) Composites for Energy Harvesting Assessment of PZT (Soft/Hard) Composites. Ferroelectrics 2020, 555, 118-123. [CrossRef] 
5. Usher, D.T.; Cousins, K.R.; Zhang, R.; Ducharme, S. The promise of piezoelectric polymers. Polym. Int. 2018, 67, 790-798. [CrossRef]

6. Yoon, C.; Jeon, B.; Yoon, G. A Feasibility Study of Fabrication of Piezoelectric Energy Harvesters on Commercially Available Aluminium Foil. Energies 2019, 12, 2797. [CrossRef]

7. Novak, N.; Keil, P.; Froemling, T.; Schader, F.; Martin, A.; Webber, K.; Roedel, J. Influence of metal/semiconductor interface on attainable piezoelectric and energy harvesting properties of ZnO. Acta Mater. 2019, 162, 277-283. [CrossRef]

8. Zheng, T.; Wu, J.; Xiao, D.; Zhu, J. Giant d33 in nonstoichiometric (K,Na)NbO3-based lead-free ceramics. Scr. Mater. 2015, 94, 25-27. [CrossRef]

9. Hayakawa, R.; Wada, Y. Piezoelectricity and related properties of polymer films. In Fortschritte der Hochpolym; Springer: Berlin/Heidelberg, Germany, 1973; pp. 1-55.

10. Brown, E.N.; Rae, E.B.; Orler, G.T.; Gray, D.; Dattelbaum, M. The effect of crystallinity on the fracture of polytetrafluoroethylene (PTFE). Mater. Sci. Eng. 2006, 26, 1338-1343. [CrossRef]

11. Sessler, G.; Hillenbrand, J. Electromechanical response of cellular electret films. Appl. Phys. Lett. 1999, 75, 3405-3407. [CrossRef]

12. Kacprzyk, R.; Motyl, E.; Gajewski, J.B.; Pasternak, A. Piezoelectric properties of nonuniform electrets. J. Electrostat. 1995, 35, 161-166. [CrossRef]

13. Hennion, C.; Lewiner, J. A new principle for the design of condenser electret transducers. J. Acoust. Soc. Am. 1978, 63, 1229-1231. [CrossRef]

14. Palitó, T.T.C.; Assagra, Y.A.O.; Altafim, R.A.P.; Carmo, J.P.; Altafim, R.A.C. Hydrophone based on 3D printed polypropylene (PP) piezoelectret. Electron. Lett. 2019, 55, 203-204. [CrossRef]

15. Mohebbi, A.; Mighri, F.; Ajji, A.; Rodrigue, D. Cellular Polymer Ferroelectret: A Review on Their Development and Their Piezoelectric Properties. Adv. Polym. Technol. 2016, 1-16. [CrossRef]

16. Paajanen, M.; Lekkala, J.; Kirjavainen, K. ElectroMechanical Film (EMFi)—A new multipurpose electret material. Sens. Actuators A Phys. 2000, 84, 95-102. [CrossRef]

17. Xue, Y.; Zhang, X. Comparative Study of Transducers for Air-borne Sound based on Normal and Irradiation Cross-linked Polypropylene Piezoelectret Films. IEEE Trans. Dielectr. Electr. Insul. 2018, 25, 228-234. [CrossRef]

18. Xue, Y.; Zhang, X. Air-coupled Ultrasonic Transducers based on Laminated Fluorinated Ethylene Propylene and Porous Polytetrafluoroethylene Ferroelectrets. IEEE Trans. Dielectr. Electr. Insul. 2017, 25, 808-815. [CrossRef]

19. Zeng, H.; Liu, Z.Z.; De Medeiros, L.J.; Kamimura, H.A.S. Optimizing dimensions of unipolar Teflon-FEP piezoelectrets with micro-system-technology. J. Phys. Conf. Ser. 2018, 1052, 1-4. [CrossRef]

20. Zúñiga, V.T.; Carmona, S.G.; Saavedra, O.G.M. Electromechanical characterization of didactical piezoelectric sensors based on crystalline grade PET Electromechanical characterization of didactical piezoelectric sensors based on crystalline grade PET. J. Phys. Conf. Ser. 2019, 1221, 1-6. [CrossRef]

21. Fang, P.; Wirges, W.; Wegener, M.; Zirkel, L.; Gerhard, R. Cellular polyethylene-naphthalate films for ferroelectret applications: Foaming, inflation and stretching, assessment of electromechanically relevant structural features. e-Polymers 2008, 8. [CrossRef]

22. Li, W.; Duan, J.; Zhong, J.; Wu, N.; Lin, S.; Xu, Z.; Chen, S.; Pan, Y.; Huang, L.; Hu, B.; et al. Flexible THV/COC Piezoelectret Nanogenerator for Wide-Range Pressure Sensing. ACS Appl. Mater. Interfaces 2018, 10, 29675-29683. [CrossRef]

23. Gerhard-Multhaupt, R. Less can be more. IEEE Trans. Dielectr. Electr. Insul. 2002, 9, 850-859. [CrossRef]

24. Zhang, X.; Wu, L.; Sessler, G.M. Energy harvesting from vibration with cross-linked polypropylene piezoelectrets. AIP Adv. 2015, 5. [CrossRef]

25. Zhang, X.; Sessler, G.M.; Wang, Y. Fluoroethylenepropylene ferroelectret films with cross-tunnel structure for piezoelectric transducers and micro energy harvesters. J. Appl. Phys. 2014, 116, 074109. [CrossRef]

26. Fang, P.; Zhuo, Q.; Cai, Y.; Tian, L.; Zhang, H.; Zheng, Y.; Li, G.; Wu, L.; Zhang, X. Piezoelectrets for wearable energy harvesters and sensors. Nano Energy 2019, 65, 104033. [CrossRef]

27. Zhang, Y.; Bowen, C.R.; Ghosh, S.K.; Mandal, D.; Khanbareh, H.; Arafa, M.; Wan, C. Ferroelectret materials and devices for energy harvesting applications. Nano Energy 2019, 57, 118-140. [CrossRef]

28. Kayaharman, M.; Das, T.; Seviora, G.; Saritas, R.; Abdel-rahman, E.; Yavuz, M. Long-Term Stability of Ferroelectret Energy Harvesters. Materials 2019, 13, 42. [CrossRef] 
29. Kacprzyk, R.; Mirkowska, A. Piezo-tubes. IEEE Trans. Dielectr. Electr. Insul. 2018, 25, 759-765. [CrossRef]

30. Altafim, R.A.P.; Qiu, X.; Wirges, W.; Gerhard, R.; Altafim, R.A.C.; Basso, H.C.; Jenninger, W.; Wagner, J. Template-based fluoroethylenepropylene piezoelectrets with tubular channels for transducer applications. J. Appl. Phys. 2009, 106, 014106. [CrossRef]

31. Rychkov, D.; Yablokov, M.; Rychkov, A. Chemical and physical surface modification of PTFE films-an approach to produce stable electrets. Appl. Phys. A Mater. Sci. Process. 2012, 107, 589-596. [CrossRef]

32. Bovtun, V.; Döring, J.; Wegener, M.; Bartusch, J.; Beck, U.; Erhard, A.; Borisov, V. Air-coupled ultrasonic applications of ferroelectrets. Ferroelectrics 2008, 370, 11-17. [CrossRef]

33. Zhang, X.; Hillenbrand, J.; Sessler, G.M. Thermally stable fluorocarbon ferroelectrets with high piezoelectric coefficient. Appl. Phys. A Mater. Sci. Process. 2006, 84, 139-142. [CrossRef]

34. Fialka, J.; Beneš, P. Comparison of Methods of Piezoelectric Coefficient Measurement. In Proceedings of the 2012 IEEE International Instrumentation and Measurement Technology Conference Proceedings, Graz, Austria, 13-16 May 2012; pp. 37-42. [CrossRef]

35. Kacprzyk, R. Influence of discharge conditions on the charge decay characteristics. J. Electrostat. 2010, 68, 190-195. [CrossRef]

36. Bednarz, J. The New Methodology for Assessing of the Applicability of Elastomeric Materials in the Vibration Isolation Systems of Railway Lines. Arch. Acoust. 2016, 41, 573-578. [CrossRef]

37. Zhukov, S.; Eder-Goy, D.; Fedosov, S.; Xu, B.-X.; von Seggern, H. Analytical prediction of the piezoelectric d33 response of fluoropolymer arrays with tubular air channels. Sci. Rep. 2018, 8, 1-10. [CrossRef]

(C) 2020 by the authors. Licensee MDPI, Basel, Switzerland. This article is an open access article distributed under the terms and conditions of the Creative Commons Attribution (CC BY) license (http://creativecommons.org/licenses/by/4.0/). 